\title{
Recent developments of kenaf fibre reinforced thermoset composites: review
}

\begin{abstract}
Kenaf fibres are recently upcoming reinforcement material to be used in composites. This is due to its low density, commercially viability, no health risk, high specific strength and modulus and renewability. It can also be cultivated in a variety of soil and is easily cultivable in some countries. Although traditionally it has been used for products such as rope, twine, bagging and rugs, recently, interests have grown for uses in other applications such as fibre reinforced composites. This paper reviews the recent developments in the use of kenaf fibre as a reinforcement material in thermoset composites. This paper also discusses the multiple types of kenaf fibres itself that are currently available in the market. The processes of kenaf cultivation and pretreatment have also been reviewed. The properties of various kenaf reinforced thermoset polymer composites, interface between kenaf fibre and matrix, and multitude of current manufacturing processes have also been discussed and presented. Recommendations for further research and development have also been given in this paper.
\end{abstract}

Keyword: Kenaf; Kenaf mechanical properties; Kenaf electrical properties; Kenaf composite interface; Kenaf treatment; Natural fibre composite; Thermoset 